\title{
Messaging Media Perceptions and Preferences: A Pilot Study in Two Distinct Cultures
}

\author{
Zixiu Guo \\ The University of New \\ South Wales \\ Sydney, Australia \\ z.guo@unsw.edu.au
}

\author{
Felix B. Tan \\ Auckland University of \\ Technology \\ Auckland, New Zealand \\ Felix.tan@aut.ac.nz
}

\author{
Tim Turner \\ ADFA@The University \\ of New South Wales \\ Canberra, Australia \\ tim.turner@adfa.edu.au
}

\author{
Huizhong Xu \\ Fudan University \\ Shanghai, China \\ hzxu@fudan.edu.cn
}

\begin{abstract}
This study empirically examines university students' perceptions and their views of when they adopt Instant Messaging (IM) and Short Messaging Service (SMS) and how they perceive and prefer these two media, in conjunction with other media (face-to-face, telephone, and email), in their university learning activities across two different cultural contexts: Australian university and Chinese university. The overall results of this study support some aspects of media richness theory. Although IM is perceived to be richer than email, it is not perceived to be the most popular medium for any situation. Data also demonstrate cultural differences in media perceptions of and preferences for new media. Specifically, Australian students have higher preference for email than their Chinese counterparts and Australian students also perceive SMS as leaner in terms of medium richness and have less preference for SMS than their Chinese counterparts.
\end{abstract}

Keywords- IM, SMS, media preference, cross-cultural study

\section{INTRODUCTION}

The rapid development and diffusion of new information and communication technologies (ICTs) have offered university students many more options for communicating with their fellows. Among these new communication media, email, Instant Messaging (IM), and text messaging in the form of SMS (Short Messaging Service) are three electronic messaging media with different forms of interactivity (synchronous vs. asynchronous) and delivered over different electronic channels (over Internet vs. mobile telephone networks). Despite the wide-spread use of IM and SMS among university students, academic interest in IM and SMS is only recent and fairly scattered [1, 2], focusing primarily on understanding and describing how and when IM and SMS are used and adopted. Many of these studies do not draw on a theoretical base (notable exceptions include [1,3]). Furthermore, these studies have considered IM or SMS in isolation. As O'Sullivan [4] noted, use of any one technology medium should be considered in light of the repertoire of other media available to fully understand when, why, and how any single medium is used. This study contributes to efforts to examine students' behaviors and their views when they adopt IM and SMS and how they perceive and choose these two media, in conjunction with other media (face-to-face, telephone, and email), in their university learning activities. As two new popular media, IM and SMS are adopted widely by younger generations $[5,6]$. Thus, understanding how students are using the IM and SMS media is of importance for a rigorous examination of the new information technologies' development, use and social effects [7]. Also, today's university students can be expected to be tomorrow's business executives and they will carry their perceptions of media with them into the workplace.

This study also attempts to shed light on how cross-cultural difference affects university students' perceptions of and preferences for these technologies. In view of increased interactions of Western educators and non-Western audiences, Stottinger et al [8] called for an improved understanding of overseas' teaching conditions and students' perspectives of technology use. There is considerable research showing the impact of culture on technology adoption and use [9]. Thus, research into investigating whether differences in technology use patterns exist among groups of students from different cultures may assist institutions to be better able to respond to the technological preferences and needs of their student customers [10]. This study reports the first part of the project aiming to explore cultural differences in university students' perceptions of and preferences for messaging media, along with traditional media, in their university learning in two culturally different universities in Australia and China. As these media become widely adopted, their importance to the general users in professional and workplace contexts is also significant.

\section{MEDIA RICHNESS AND PREFERENCES}

Media richness theory proposes that (a) media differ in richness; (b) tasks differ in information processing requirements; and (c) performance improves when managers use richer media for equivocal tasks and leaner media for unequivocal tasks $[11,12]$. Highly equivocal tasks call for richer media that allow a higher degree of personal interaction, while less equivocal tasks can be performed through lean media. The "medium-task fit" explanation of media choice is supported by strong evidence, while empirical and anecdotal evidence illustrates sometimes contrasting views on why new technologies are selected, the tasks for which they are best suited, and people's perceptions of these media.

This study builds on previous research that investigated media richness ranking and examined media richness theory in traditional and new messaging media landscapes. According to 
media richness criteria, IM interaction supports the higher level of interactive activities by providing continuous feedback during the interaction, without various social cues and body language available due to the lack of physical presence. SMS provides less support for interaction, no social cues and body language are available. However, no empirical studies have been conducted to examine how IM and SMS are placed in media richness ranking, compared to traditional and other new media. Little is known how IM and SMS are preferred by university students for tasks that require different levels of media richness. The goal of this study is to explore the media richness ranking and the preferences for this wider range of communication media. These research questions guided this study:

RQ1: How are IM and SMS ranked in terms of media richness, compared to face-to-face, telephone, and email?

RQ2: How are IM and SMS preferred for communication activities theoretically requiring different levels of richness, compared to face-to-face, telephone, and email?

\section{CROSS-CULTURAL DIFFERENCES IN MEDIA RICHNESS AND PREFERENCES}

The growing multicultural nature of our classrooms should drive educators to explore the impact of culture on students' perceptions of and preferences for media in their collaborative learning within culturally heterogeneous groups. Numerous cross-cultural social psychology studies have demonstrated that culture and communication are closely related [13, 14]. Crosscultural studies have shown that cultures vary on several value dimensions including, perhaps most significantly, their level of individualism versus collectivism, and the related concepts of "high-context" and "low-context" communication style [14, 15]. According to Hofstede (1980), the individualismcollectivism dimension is a conglomeration of values concerning the relation of an individual to his or her collectivity in society. Individualism is a preference for a loosely-knit social framework wherein individuals are supposed to take care of themselves and their immediate families only. Australia is a typical individualistic culture. Its opposite, collectivism, represents a preference for a tightly-knit social framework in which individuals can expect their relatives, clan, or other in-group to look after them in exchange for unquestioning loyalty [16]. People from a collectivistic culture value security, obedience, and harmony within the team and maintain relatively tight-knit or cohesive groups; they are more group oriented and promote group identity. Chinese culture is typically highly collectivistic.

How culture influences students' perceptions of and preferences for SMS and IM has not been explored in prior research. Thus, the following research questions are proposed.

RQ3: Are IM and SMS media richness being ranked differently across cultures?

RQ4: Are IM and SMS being preferred differently for accomplishing each specific communication activity across cultures?

\section{RESEARCH METHOD}

Data for this study were collected through a survey both in China and Australia. As this was a pilot study, the participants were 52 undergraduate students in a large university in China and 50 undergraduate students from a large university in Australia. The average age of the Chinese subjects participating in the study was 19 years and $60 \%$ were male. All Chinese participants have Chinese ethnic background. The average age of the Australian subjects participating in the study was 20 years and $74 \%$ were male. All Australian participants have Australian ethnic background. All materials were translated into Chinese, and then translated back to ensure that the Chinese version of the questionnaire represented the intent and spirit of original documents and were not merely a literal translation. All participants completed the questionnaire in their native language. The questionnaire was completed in classrooms and required approximately 20 minutes to complete.

Measures of individualism-collectivism dimension were borrowed from Earley's [13] work. A satisfactory reliability of .79 was achieved with six items. Perceived media richness was measured with a 4-item scale developed by D'Ambra and Rice [17] across five available media: face-to-face communication, the telephone, email, IM and SMS. The reliabilities of these scales also were generally satisfactory $(.65, .72, .73, .77$, and .79 for face-to-face, telephone, email, IM and SMS respectively).

Media preference was measured by ranking of preferred media for each of the six communication activities that students used to communicate with their group members. These communication tasks were borrowed from D'Ambra and Rice's [17] work and revised to fit into university contexts. For each communication activity, for each medium, rankings were scaled as $1=$ chosen 5 th, $2=$ chosen 4 th, $3=$ chosen $3 \mathrm{rd}$, 4=chosen 2nd, and $5=$ chosen 1 st.

\section{RESULTS}

The manipulation on national culture was checked using items measuring the individualism-collectivism dimension. Chinese students were much lower on the index of individualism than Australian students. A t-test analysis confirmed the significance of this difference $(t(100)=12.14$, $\rho<0.001)$. Therefore, the planned comparison could be made.

There were significant media richness differences across traditional and messaging media. Overall $(\mathrm{F}(4,505)=121.89$, $\mathrm{p}<.001)$ and in each cultural group $(\mathrm{F}(4,255)=34.40, \mathrm{p}<.001$; $\mathrm{F}(4,245)=135.10, \mathrm{p}<.001$ for China and Australia respectively). Face-to-face was perceived to be richest, followed in decreasing order by telephone, IM, email and SMS, which is consistent with media richness theory. As the equivocality of the task decreased, face-to-face and telephone ranking generally decreased, email ranking increased, IM ranking did not change much, and SMS ranking slightly increased. However, IM and SMS were never being chosen as the first preferred media for any situation.

Although the ranking of media richness was in the same decreasing order of face-to-face, telephone, IM, email, and 
SMS for each cultural group, Chinese students rated IM $(\mathrm{t}=2.11, \mathrm{p}<.05)$ and $\operatorname{SMS}(\mathrm{t}=5.03, \mathrm{p}<.001)$ as significantly more rich, compared to their Australian counterparts.

Results also indicate the significant cultural level differences in email and SMS messaging media mean preferences. Australian students had a significantly higher preference for email $(\mathrm{t}=5.47, \mathrm{p}<.001)$, compared to Chinese students. In contrast, Chinese students had significantly higher preferences for SMS $(\mathrm{t}=4.87, \mathrm{p}<.001)$, compared to Australian students. Consistent results were obtained from the individuallevel comparisons by situations. So, email and SMS seemed to provide the clearest distinction between students in these two different cultural contexts

\section{DISCUSSION AND CONCLUSION}

The possible reason for IM and SMS not being preferred in conformance with MRT, is that IM and SMS are still new to the students. Despite their increasing utility in students' study and personal life, the diffusion and adoption of these two media are still in their early stage, compared to email diffusion and adoption. Thus, the low ratings for their preferences may reflect unfamiliarity and unrefined use of them for communication. This result echoes what happened to email at the time it was introduced [19], when Rice noted that "stable and higher assessments of email might await greater diffusion and familiarity" (p.479).

Comparing to IM and SMS, email has become an "old" communication medium in most people's life, especially in modern countries, such as Australia. Thus, it is not surprising that Australian students have higher preferences for email than their Chinese counterparts. In this study, we found that Australian students perceived email to be equivalent with telephone in fulfilling most of their communication tasks, while Chinese students perceived email to be equivalent with IM and SMS in fulfilling certain communication activities.

One of the possible reasons for Chinese students favoring SMS more than Australian students is the different degree of need for intimacy and social intercourse [20]. Another advantage of SMS is that its asynchronicity allows users time for reflection before having to respond, which allows greater face-management [21], an important concern for Chinese people. The third possible reason is related to the characteristics of Chinese language. Since Chinese students sent their SMS in Chinese ideographs, a limited string would be more information rich than the same length of alphabetic characters in English. Therefore, Chinese students may perceive SMS as richer and consequently prefer it more than their Australian counterparts.

This paper has pragmatic importance for managing multinational universities' information technology adoption, implementation, and diffusion. This paper indicates that multinational universities should at least be aware of the cultural differences and prepare for the potential differences in responses of students to these systems. Otherwise, it may be that the advantage of the technological innovation will not offset the burdens of cultural change and lead to a difficult and prolonged adaptation [22]. Furthermore, it shows that email, a new information technology medium, can be employed in much the same way as traditional media in fulfilling most communication requirements in Australia, where diffusion has progressed substantially, but not in China where email is still treated as a new medium, perceived differently from traditional media. Thus, Chinese students who came to Australia for their university study might encounter the problem of having different email usage pattern with their local follows in their own study as well as group collaborating works. However there were no data collected from those Chinese students who study in Australia. Further study needs to consider this aspect in order to explore whether those Chinese students' media use pattern will move away from their peers in China and toward the pattern of use exhibited by the Australian students, thereby suggesting the influence of educational context on how students set their learning [23].

\section{REFERENCES}

[1] A. F. Cameron and J. Webster, "Unintended consequence of emerging communication technologies: Instant messaging in the workplace," Computers in Human Behavior, vol. 21, pp. 85-103, 2005.

[2] J. Rennecker, A. R. Dennis, and S. Hansen, "Reconstructing the stage: The use of instant messaging to restructure meeting boundaries," in Proceedings of the Thirty-ninth Hawaii International Conference on System Sciences, Kauai, Hawaii, 2006.

[3] B. A. Nardi, S. Whittaker, and E. Bradner, "Interaction and outeraction: instant messaging in action," in Proceedings of the ACM Conference on Computer-Supported Cooperative Work, Philadelphia, PA, 2000, pp. 7988.

[4] P. B. O'Sulliean, "what you don't know won't hurt me: Impression management functions of communication channels in relationships," Human Communication Research, vol. 26, pp. 403-431, 2000.

[5] R. E. Grinter and L. Palen, "Instant messaging in teen life," in Proceedings in the ACM Conference on Computer-Supported Cooperative Work, New Orleans, LA, 2002.

[6] H. Nysveen and P. E. Pedersen, "Individual and cross media communication in converging media environments: A review of research on the antecedents and effects of communication using various media in marketing contexts." vol. 2004 Bergen: SNF Working Paper No. 26/03. Foundation for Research in Economics and Business Administration, Bergen, Norway., 2002.

[7] A. J. Flanagin and M. J. Metzger, "Internet use in the contemporary media environment," Human Communication Research, vol. 27, pp. 153-181, 2001

[8] B. Stottinger and B. B. Schlegelmilch, "Information and communication technologies in tertiary education: A "customer" perspective," Marketing Education Review, vol. 12, pp. 63-72, Summer 2002.

[9] Z. Guo, J. D'Ambra, T. Turner, and H. Zhang, "Improving Virtual Team Effectiveness: A Cross-Cultural Comparison," in Proceedings of the 2006 Mediterranean Conference on Information Systems, San Servolo, Venice, Italy, 2006.

[10] T. F. Stafford, "Understanding motivations for Internet use in distance education," IEEE Transactions on Education, vol. 48, pp. 301-306, 2005.

[11] R. L. Daft and R. H. Lengel, "Organizational information requirements, media richness and structural design," Management Science, vol. 32, pp. 554-571, 1986

[12] R. L. Daft, R. H. Lengel, and L. K. Trevino, "Message equivocality, media selection, and manager performance: Implications for information systems," MIS Quarterly, vol. 11, pp. 355-366, 1987.

[13] P. C. Earley, "East meets west meets mideast: Further explorations of collectivistic and individualistic work groups," Academy of Management Journal, vol. 36, pp. 319-348, 1993.

[14] G. Hofstede, Culture's Consequence: International Differences in WorkRelated Values. Beverly Hill, CA: Sage Publications, 1980.

[15] E. T. Hall, Beyond Culture. New York: Doubleday, 1976. 
[16] M. Erez and P. Earley, Culture, Self-Identity and Work. Oxford: Oxford University Press, 1993.

[17] J. D'Ambra and R. E. Rice, "Multimethod approaches for the study of computer-mediated communication equivocality, and media selection," IEEE Transactions on Professional Communication, vol. 37, pp. 231239, 1994.

[18] D. L. Goodhue, "Understanding user evaluations of information systems," Management Science, vol. 41, pp. 1827-1844, 1995.

[19] R. E. Rice, "Media appropriateness: Using social presence theory to compare traditional and new organizational media," Human Communication Research, vol. 19, pp. 451-484, 1993.

[20] C. Thurlow and A. Brown, "Generation Txt? The sociolinguistics of young people's text-messaging," in Annual Conference of the British Association of Applied Linguists, Cardiff, 2002.
[21] R. Ling and B. Yttri, "Hyper-coordination via mobile phones in Norway," in Perpetual Contact: Mobile Communication, Private Talk, Public Performance, E. James, J. E. Katz, and M. A. Mark, Eds. Cambridge: Cambridge University Press, 2002, pp. 139-169.

[22] W. Straub, "The effects of culture on IT diffusion: E-mail and Fax in Japan and the USA," Information Systems Research, vol. 5, pp. 23-47, 1994.

[23] N. Purdie and J. Hattie, "Cultural differences in the use of strategies for self-regulated learning," American Educational Research Journal, vol. 33, pp. 845-871, 1996. 